\title{
Medkulturnost v pravljicah Dorotheae Viehmann, Laure Gonzenbach in Tine Vajtove ob primeru pravljic o začarani nevesti (ATU 402)
}

\section{Milena Mileva Blažić}

In the article, three female storytellers are compared - Dorothea Viehmann, Laura Gonzenbah and Tyna Wajtawa, with an investigation of their narrative repertoire and their socio-cultural background. Their fairy tales reflect multilingualism and interculturalism, with the influence of elements of German, Romance and Slavic cultures. Based on the comparative analysis of the ATU folktale types, it was discovered that they have all included in their repertoire a fairy tale of the folktale types ATU 402 (animal bride) and ATU 425 (searching for a lost husband). The article includes a comparative analysis of the similarities and differences of their variants of fairy tale type ATU 402 "The Animal Bride".

KEYWORDS: women fairy tale writers, women storytellers, Dorothea Viehmann, Laura Gonzenbach, Tyna Wajtawa, ATU 402, language, literature, culture

\section{PRVE OMEMBE ŽENSKIH PRAVLJIČARK}

V monografiji The Classic Fairy Tales (1999), ki jo je uredila Maria Tatar, je Karen E. Rowe v poglavju »To Spin a Yarn: The Female Voice in Folklore and Fairy Tales« navedla dve metafori za pravljičarki, in sicer za prvi model - pisateljice - navaja antični mit o Filomeli (Ovid, Metamorfoze, knjiga VI), ki je bila na podlagi mita viktimizirana ter dobesedno in metaforično brez jezika, nato pa je svojo zgodbo vtkala v tapiserijo ter jo poslala sestri v branje. ${ }^{1}$

Mit o Filomeli iz Ovidovih Metamorfoz govori o Filomeli, hčeri atenskega kralja Pandiona, ki jo je posilil svak Terej in ji nato odrezal jezik. Ker o tem ni mogla pripovedovati, je svojo zgodbo vtkala v tapiserijo oz. jo vizualno ubesedila ter jo poslala svoji sestri Prokne. Nato sta skupaj umorili Terejevega sina in mu ga pripravili kot obrok. Ko je mož ugotovil, da je pojedel lastnega sina, ju je zasledoval, toda bogovi so spremenili Filomelo v slavčka, Prokne v lastovko in Tereja v smrdokavro.

\footnotetext{
1 Motiv žensk - predic in tkalk je tudi v Svetem pismu: »Pohvala vrli ženi. Svoje roke izteguje k preslici, njene dlani prijemajo vreteno« (Prg 31,19). »Vse spretne žene so s svojimi rokami predle in prinesle, kar so napredle: višnjev in rdeč škrlat, karmezin in tančico« $(2 \mathrm{Mz} 28,5)$. »[...] in kjer so ženske tkale ogrinjala« (2 Kr 23,7) (Biblija 2016).
} 
V Apulejevih Metamorfozah oz. v znamenitem mitu o Erosu in Psihi pa nastopa poleg glavnega pripovedovalca Lucija oz. zlatega osla tudi pripovedovalka - okajena starka (Ziolkowski 2006: 58).

Tako je o ugrabljeni deklici (Psihi) pripovedovala prismojena in okajena starka, meni [Luciju] pa, ki sem stal zraven, je bilo od srca žal, da nimam pri sebi ne tablice ne pisala in ne morem zapisati tako očarljive pravljice (Apulej 1981: 178).

Začetke ženskega avtorstva najdemo v pesmih srednjeveških trubadurk (12.-13. stol.) in tematiki fin'amor, ki pripoveduje o dvorski ljubezni in predstavlja srednjeveški evropski koncept ljubezni in občudovanja med plemstvom.

Tudi v zbirki arabskih pravljic Tisoč in ena noč, ki so v Evropo prišle s prevodom v francoščino (1702-1717), je osrednja pripovedovalka Šeherezada, ki je postala v Utherjevem indeksu pravljični tip pod tipno številko ATU 875B*»Storytelling Saves a Wife from Death (Sheherazade)« (»Pripovedovanje pravljic reši ženo pred smrtjo (Šeherezada)《).

Pripovedovalke zgodb najdemo tudi v Boccacciovem Dekameronu, kjer je med desetimi pripovedovalci sedem pripovedovalk (Elissa, Emilia, Fiammetta, Filomena, Lauretta, Neifile in Pampinea).

V Canterbury Tales (Canterburyjske zgodbe, 1483) Geoffreyja Chaucerja sta poleg 14 moških pripovedovalcev (berač, duhovnik, gospod, mlinar, odpustkar, oskrbnik, pomorščak, posestnik, pravnik, trgovec, učenjak, upravnik, vitez, zdravnik) dve pripovedovalki (gospodinja iz Batha in mati prednica). Pripoved Gospodinje iz Batha se motivno-tematsko navezuje na motiv živalskega ženina/neveste oz. Amorja in Psihe.

Prva zbirka pravljic Giovannija Francesca Straparole Le piacevoli notti (Prijetne noči, 1551-1553) je bila namenjena odraslim bralcem. Pripovedovanje poteka v visokem sociokulturnem okolju na otoku Murano pri Benetkah. Tudi v posvetilu so nagovorjene ženske. Osrednja oseba ali beneška Madona je plemenita Signora Lucretia. Zgodbe pripoveduje poleg pripovedovalcev tudi deset pripovedovalk (Arianna, Cateruzza, Brunetta, Eritrea, Fiordiana, Isabella, Lauretta, Lionora, Lodovica, Vicenza). Med pravljicami je tudi »Obuti maček« (ATU 545B »Puss in Boots«), ki jo najdemo tudi v pravljičnih zbirkah Gianbattiste Basileja (Pentamerone II, 4) in Charlesa Perraulta (Le Maitre de Chat ou Le Chat botté 1697).

V zbirki pravljic za odrasle Gianbattiste Basileja Pentamerone (1634, 1636), ki je danes znana kot prva zbirka pravljic za odrasle »in mlade« (The Tale of Tales, or Entertainment for Little Ones), so vse pripovedovalke ženske, osrednja je Zoza, poleg nje pa še Antonia, Diana, Domenica, Francesca, Giacoma, Girolama, Giulia, Lucrezia, Vittoria, Pozia in Paola. ${ }^{2}$

Značilnost francoskih pravljičark - precioz je, da so v literarnih salonih pripovedovale zgodbe, katerih tekst je namenjen otrokom, kontekst pa odraslim (Seifert 2006: 45). Sociokulturno so bile precioze plemkinje, torej aristokratskega porekla, ki so pripovedovale

\footnotetext{
2 V zbirki pravljic je Basile plemiška imena nadomestil s komičnimi Antonella, Cecca, Ciulla, Ciommetella, Iacova, Meneca, Paola, Popa, Tolla, Zoza.
} 
pravljice po dvorcih. Kljub temu so njihove pravljice močno vplivale na razvoj pisanja pravljic po vsem svetu, saj so ravno one redefinirale trubadursko tematiko fin'amor $\mathrm{v}$ pravljično tematiko (npr. Zala in Zver), njihovo pripovedovanje v dvorcih je bilo »salonska igra« (Seifert 2006: 45).

Najbolj znana otroška zbirka pravljic Kinder- und Hausmärchen (Otroške in hišne pravljice) bratov Jacoba in Wilhelma Grimma je prvič izšla leta 1812 (1. knjiga) in leta 1815 (2. knjiga), nato pa je doživela še več dopolnjenih izdaj. Tudi v tej zbirki so zbrane pravljice, ki so jih po večini pripovedovale ženske. Najbolj znana med njimi je Dorothea Viehmann.

\section{DOROTHEA VIEHMANN (1755-1815)}

Dorothea Viehmann (roj. Katharina Dorothea Pierson) je ena od najpomembnejših pravljičark Jacoba in Wilhelma Grimma. Prispevala je okrog 36 (od 210) pravljic (Ehrhardt 2012: 148-149), ki so objavljene predvsem v drugem zvezku Kinder- und Hausmärchen $(K H M, 1815)$. Njen oče Isaac Pierson je bil gostilničar, čigar predniki so se preselili v deželo Hessen-Kassel zaradi pregona hugenotov v Franciji. Leta 1777 se je Dorothea poročila s krojačem Nikolajem Viehmannom in se leta 1787 preselila v Niederzwehren (danes del Kassla), kjer je živela do leta 1815. Po moževi smrti je s kmečkim delom (in kot branjevka) preživljala sebe in sedem otrok. Leta 1813 je spoznala brata Grimm in jima tedensko pripovedovala pravljice. Na njene pravljice je vplivalo sociokulturno okolje kmečko življenje in delo v gostilni; poleg tega pa vsebujejo tudi francoske prvine. Brata Grimm sta bila vesela, da sta spoznala pravljičarko, ki jima je pripovedovala pravljice vedno s skoraj istimi besedami, če jih je morala ponoviti. Obiskovala ju je je od 29. maja 1813 do 4. septembra 1814 (Ehrhardt 2012: 17). Septembra 2012 so dotlej neznano sliko v Univerzitetni knjižnici v Kasslu identificirali kot portret Dorothee Viehmann, ki ga je ustvaril Ludwig Emil Grimm, Jacobov in Wilhelmov mlajši brat. Ena od pravljic, ki jih je Dorothea povedala bratoma Grimm, je KHM 106 Siromašni mlinarček in mucka (Der arme Müllerbursch und das Kätzchen). Pri tej pravljici je močno opazno, da se navezuje na francosko pravljico Bela mačka (La chatte blanche) avtorice Madame d'Aulnoy (Marie-Catherine, baronica d'Aulnoy, 1650-1705), pa tudi na basen La Fontaina (1621-1695) Mačka in stara podgana ${ }^{3}$ (1694), ki je tematsko povezana z Ezopovimi basnimi.

Dorothea Viehmann pa ni bila edina pravljičarka bratov Grimm, saj so jima pravljice pripovedovale še druge, med njimi tudi sestre Hassenpflug (Amalie, Johanna, Marie) in Wild (predvsem Dorothea, pozneje Wilhelmova soproga).

\section{LAURA GONZENBACH (1842-1878)}

Laura Gonzenbach se je rodila leta 1842 v bogati švicarsko-nemški protestantski družini v Mesini na Siciliji, Tako kot njeni štirje sorojenci je bila deležna dobre izobrazbe v zasebni

3 http://classes.bnf.fr/livre/grand/382.htm 
šoli. Ko je bila stara pet let, ji je umrla mati, zato je zanjo skrbela sestra Magdalena, ki je bila izredna mlada ženska - svetovljanka, izobražena in z naprednimi pogledi na položaj žensk. Laura je že v otroštvu govorila štiri jezike (nemško, francosko, italijansko in sicilijansko). Igrala je številne inštrumente ter znala na pamet številne antične pesmi. Takrat ženske niso mogle študirati na univerzi, zato so sestre Gonzenbach imele salon in se udeleževale neformalnega izobraževanja $\mathrm{v}$ drugih salonih, kjer so razpravljali o umetnosti, srečevale so umetnike in razpravljale o položaju žensk. Takrat se je v salonih začelo razvijati pripovedovanje zgodb. Laura se je poročila pri 27 letih in imela pet otrok ter živela v Neaplju. Umrla je v 36. letu.

V njeni mladosti je nanjo vplival dr. Otto Hartwig, ki je pet let vodil nedeljske maše za nemško in švicarsko skupnost v Mesini. Hartwig je organiziral tamkajšnje kulturno življenje in začel zbirati sicilijanske pravljice. Za Lauro je menil, da je ena najbolj nadarjenih pripovedovalk, zato ji je predlagal, naj izbere nekaj pravljic in jih zapiše, saj sam ni razumel siciljanščine. Leta 1870 je izdala Sizilianische Märchen, knjigo je uredil Otto Hartwig. Laura je odlično znala tamkajšnji jezik, zato si je zapisovala zgodbe, ki so jih pripovedovale sicilijanske ženske. Očitno je Gonzenbachova poznala nemške, verjetno Grimmove pravljice, mogoče celo francoske. Zanimivo je, da je pravljice odlično prevedla v nemščino, čeprav ni nikoli živela niti v Nemčiji niti v Švici. Hartwig in Kohler (izdajatelja sicilijanskih pravljic) njenih zapisov nista veliko spreminjala, nista jih olepševala, pustila sta tudi nasilne konflikte, saj so zgodbe tako pripovedovali.

Številne sicilijanske ženske so lahko zapustile dom le ob poroki, zato so mnoge pobegnile od doma, potovale, se zaposlovale kot pestunje. Če primerjamo motivno-tematsko podobo pravljic v Grimmovi in Gonzenbachovi inačici, lahko ugotovimo, da so Grimmove ženske npr. v Kosmatinki in Motovilki pasivne žrtve, ki so kaznovane, ko želijo pobegniti ali se osamosvojiti. Pri Lauri Gonzenbach pa so v pravljicah Lepa Angiola, Lignu di Scupa, Betta Pilusa pravljične osebe močne, tvorne in nimajo vloge žrtve. Ženske junakinje so svojo usodo vzele v lastne roke, na poti so jih dobesedno in $\mathrm{v}$ prenesenem pomenu čakali številni nasilneži, tudi sadistični morilci (The Story About Ohmy, The Robber with a Witch's Head). Zbirko ljudskih pravljic Laure Gonzenbach je težko razglasiti za feministično ali subverzivno, še težje pa je zanikati, da ima te prvine.

Sicilijanske pravljice so pripovedovali tudi otrokom, ne le odraslim, vendar niso očiščene nasilnih prizorov in nasilnežev. Njihov namen je bil, kot je zapisala Laura Gonzenbach, ohraniti avtentičnost pripovedovanja, ne pa spreminjati in prilagati zapisano. Zanimivo je, da jih ni zapisala v sicilijanščini, ampak jih je sproti prevajala v nemščino, pri čemer ji je pomagala sestra Magdalena.

Zbirko sicilijanskih pravljic Laure Gonzenbach Sizilianische Märchen (1870) je v italijanščino prevedla Luise Rubini kot Fiabe siciliane (1999) in dodala uvod ter komentarje, iz italijanščine pa jih je v angleščino prevedel vodilni literarni zgodovinar Jack Zipes. Najprej je prevedel prvi del Beautiful Angiola (Zipes 2003), potem še drugi del The Robber with a witch's head (Zipes 2004), zatem sta izšla oba dela v integralni verziji Beautiful Angiola: The Lost Sicilian Folk and Fairy Tales of Laura Gonzenbach (Zipes 2006). Šele s prvim, drugim in celotnim prevodom v angleščino ter s predgovorom in opombami Jacka Zipesa je zbirka dobila zasluženo mesto v literarni zgodovini. 
Zipes je v drugi izdaji Beautiful Angiola vsem 94 pravljicam dodal številke ATU in kratko razlago tipa/motiva. V spremni besedi je življenje in delo Laure Gonzenbach kot tudi njene pravljice postavil v sociokulturni kontekst. Navedel je tudi nekaj pripovedovalk (informantk): Gua Lucia, Gua Cicca Crialesi, Gua Nunzia Giuffridi, Bastiana, Elisabetta in Concetta Martinotti, Francesca Rusullo, Peppina Guglielmo, Caterina Certo.

\section{TINA VAJTOVA (1900-1984)}

Valentina Pielich, poročena Negro, z domačim imenom Tina Vajtova, se je rodila 4. maja 1900 na Ladini pri Solbici (Rezija, dolina v Videmski pokrajini v deželi Furlanija - Julijska krajina, Republika Italija; avtohtoni jeziki v Videmski pokrajini so furlanščina, italijanščina, nemščina in slovenščina).

Bila je ena od štirih otrok (dve hčerki, dva sinova) očeta brusarja Giosuepa Pielicha Vajta (1861-1904) in matere Žvane Siega (1861-1930), z domačim imenom Mucove iz Osojan. Družina je doživela veliko tragedij: oče je zmrznil v snegu, starejši brat je utonil, mlajši se je smrtno ponesrečil. Že kot deklica je hodila z materjo od vasi do vasi, kupovali in prodajali sta lase, potem glavnike, gumbe, naprstnike, sukanec, trakove ipd. ter tako preživljali družino. Na teh poteh sta prenočevali v naravi, v hlevih, na kmetijah ipd. Tini so se vtisnile v spomin različne pravljice, pesmice, pregovori, uganke, šege, navade, spomini, dogodivščine ipd., ki jih je slišala na teh poteh, tudi od svoje matere.

Hodila je v osnovno šolo in zaključila dva ali tri razrede. Leta 1921 se je poročila z brusarjem Žvanom Negrom (1898-1953); rodila je osem otrok (štiri hčerke in štiri sinove). Žal so štirje umrli že v zgodnjem otroštvu, trije pa pozneje. Otroštvo je preživela le hčerka Gelinda (1937-), ki še danes živi v Pordenonu v Italiji. Tudi njeno življenje je bilo prežeto s tragičnimi dogodki, med drugim ji je mož pri 29 letih umrl v prometni nesreči. Ostala je sama z dvema otrokoma, zato se je Tina preselila k njej v Pordenone. Tudi Gelinda pripoveduje pravljice. Tina je zadnjih deset let življenja (1974-1984) bolehala, vendar je vsako poletje preživela v rojstni Solbici. Umrla je 21. februarja $1984 \mathrm{v}$ Pordenonu, kjer je tudi njeno zadnje počivališče.

Milko Matičetov (1919-2014), ki je raziskoval življenje in delo Tine Vajtove, je zapisal njen življenjski moto: »Kaj bi človek jokal, saj je že tako dovolj hudo na svetu!« Matičetov je bil prepričan, da so ji pravljice pomagale prenašati življenjske tragedije, saj je sama nekoč dejala, »da bi šla za eno pravljico po kolenih v Benetke ter da bi za njih skočila v ogenj ali vodo« (Matičetov 1984: 328). Matičetov je posnel kar 404 pravljice, ki jih je pripovedovala Tina Vajtova, okrog 27 jih je objavil v italijanščini, rezijanščini in slovenščini. Leta 1967 so za TV Slovenija posneli serijo dokumentarnih filmov Pri naših pravljičarjih, $\mathrm{v}$ enem od njih pripoveduje tudi Tina Vajtova. ${ }^{4}$

\footnotetext{
${ }^{4}$ Milko Matičetov: Tina Vajtova [videoposnetek]: Solbica; scenarij Milko Matičetov, kamera Slavko Nemec, režija Emil Rižnar. Pri naših pravljičarjih. Ljubljana. Hrani: Avdiovizualni laboratorij Inštituta za slovensko narodopisje ZRC SAZU, [2012], 1968.
} 
Sociokulturno ozadje

\begin{tabular}{|c|c|c|c|}
\hline & $\begin{array}{l}\text { Viehmann, Dorothea } \\
(1755-1816)\end{array}$ & $\begin{array}{l}\text { Gonzenbach, Laura } \\
(1842-1878)\end{array}$ & $\begin{array}{l}\text { Vajtova, Tina } \\
(1900-1984)\end{array}$ \\
\hline $\begin{array}{l}\text { - sociokulturni } \\
\text { kontekst }\end{array}$ & $\begin{array}{l}\text { - ena izmed } 13 \text { otrok } \\
\text { - obrtniki, srednji } \\
\text { razred } \\
\text { - oče gostilničar }\end{array}$ & $\begin{array}{l}\text { - oče trgovec, konzul } \\
\text { - zgodnja smrt } \\
\text { matere } \\
\text { - ena izmed } 8 \text { otrok } \\
\text { - zasebno šolanje } \\
\text { - zgodnja smrt } \\
\text { matere }\end{array}$ & $\begin{array}{l}\text { - oče delavec } \\
\text { (obrtnik) in mati } \\
\text { prodajalka } \\
\text { - ena izmed } 4 \text { otrok } \\
\text { - nižji socialni } \\
\text { položaj } \\
\text { - kmečki sloj }\end{array}$ \\
\hline - jeziki in kultura & $\begin{array}{l}\text { - Nemčija } \\
\text { - Francija }\end{array}$ & $\begin{array}{l}\text { - Italija } \\
\text { - Švica } \\
\text { - Sicilija } \\
\text { - Malta }\end{array}$ & $\begin{array}{l}\text { - Italija } \\
\text { - Slovenija } \\
\text { - Rezija }\end{array}$ \\
\hline - družina & $\begin{array}{l}\text { - mati } 7 \text { otrok } \\
\text { - smrt moža }\end{array}$ & $\begin{array}{l}\text { - } \text { mati } 5 \text { otrok } \\
\text { - zgodnja smrt (36 } \\
\text { let) }\end{array}$ & $\begin{array}{l}\text { - mati } 8 \text { otrok (le } \\
1 \text { preživel), smrt } \\
\text { moža }\end{array}$ \\
\hline $\begin{array}{l}\text { pisateljice in/ali } \\
\text { pripovedovalke }\end{array}$ & - pripovedovalka & 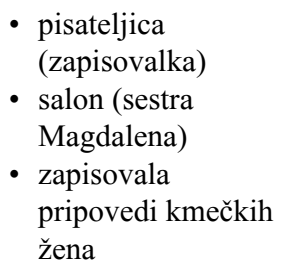 & - pripovedovalka \\
\hline - spodbuda & - J. in W. Grimm & - Otto Hartwig & - Milko Matičetov \\
\hline - število enot & - 36 & - 92 & - 404 \\
\hline
\end{tabular}

\section{JEZIK, LITERATURA IN KULTURA - PRIMERJALNA ANALIZA PRAVLJIC TIPA ATU 402}

Vse tri pravljičarke - Dorothea, Laura in Tina - imajo v svojem repertoarju isti pravljični tip ATU 402. Dorotheina pravljica je nastala v germanskem, Laurina v romanskem in Tinina v slovanskem kontekstu, hkrati pa $\mathrm{v}$ vseh treh variantah najdemo podobnosti in razlike. Pravljični motiv živalskega ženina (ali neveste) omogoča čustveno, poetično izražanje pripovedovalk in pisateljic.

Na podlagi primerjave pravljic Dorothee Viehmann, Laure Gonzenbach in Tine Vajtove je ugotovljeno, da so vsem trem pravljičarkam skupni naslednji pravljični tipi. 


\begin{tabular}{|c|c|c|c|}
\hline & Viehmann, Dorothea & Gonzenbach, Laura & Vajtova, Tina \\
\hline $\begin{array}{l}\text { - ATU } 400 \text { The Man } \\
\text { on a Quest for his } \\
\text { lost wife }\end{array}$ & $\begin{array}{l}\text { - Der König vom } \\
\text { goldenen Berg (92) }\end{array}$ & $\begin{array}{l}\text { - About Joseph, Who } \\
\text { Set out to Seek His } \\
\text { Fortune }(81)^{5}\end{array}$ & 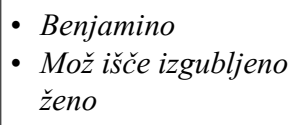 \\
\hline $\begin{array}{l}\text { - ATU } 402 \text { The } \\
\text { Animal Bride (The } \\
\text { Mouse (Cat, Frog, } \\
\text { etc.) as Bride); }\end{array}$ & $\begin{array}{l}\text { - Die drei Federn, } \\
\text { KHM } 106 \\
\text { - Der arme } \\
\text { Müllersbursch und } \\
\text { das Kätzchen, KHM } \\
106\end{array}$ & $\begin{array}{l}\text { - The Wasteful } \\
\text { Giovanninu (82) }\end{array}$ & - Žabica (T 38 D) ${ }^{6}$ \\
\hline $\begin{array}{l}\text { - ATU } 425 \text { The } \\
\text { search for the } \\
\text { lost husband, } \\
\text { The animal as } \\
\text { bridegroom }\end{array}$ & $\begin{array}{l}\text { - Der Eisen-Ofen } \\
1815 \text { (št. 41), od } \\
1837 \text { Der Eisenofen } \\
\text { (KHM 127) }\end{array}$ & $\begin{array}{l}\text { - Prince Scursuini } \\
\text { (12) } \\
\text { - The Pig King (37) }\end{array}$ & $\begin{array}{l}\text { - Dekle, ki je hotela } \\
\text { rožico } \\
\text { - Zelenec }\end{array}$ \\
\hline
\end{tabular}

Vse tri obravnavane pravljice so klasificirane kot pravljični tip ATU $402 »$ The Animal Bride«, kar je podobnost, razlika pa je, da je v pravljici Tri peresa (KHM 106) živalska nevesta grda žaba, v Nespametnem Giovanninu (Zipes 2006: 502) bela ovca in v Žabici (Kropej, Dapit 2018: 79-85) žabica.

Vse tri pravljične živalske neveste so povezane z motivom tkanja (Filomenin motiv): $\mathrm{v}$ prvi gre za najlepšo laneno tkanino, v drugi za dvanajst srajc iz najfinejše tkanine in $\mathrm{v}$ tretji za sukno, tkano iz najfinejše niti, da lahko gre skozi prstan, kar je podobnost med Dorotheino in Tinino varianto.

Pravljica Nespametni Giovanninu bi lahko bila antipravljica (Lüthi 1987: 54), ker je pravljični lik Giovanninu nespameten, pada iz sreče v nesrečo, iz bogastva v revščino. Ima zvestega službanika Peppeta, kar se motivno-tematsko povezuje z motivom Don Kihota in Sancha Panse ter grofa Lukanorja in zvestega Patronia (Don Juan Manuel).

Vsi trije pravljični junaki, Tepko, Giovanninu in tretji brat kraljevič, so popotniki, ki odidejo od doma: v prvi pravljici gre Tepko po lan, preprogo in lepotico, v drugi pravljici Giovanninu sreča živalsko nevesto - belo ovco, vendar zaradi uročenosti zaspi in ne opravi svoje naloge v osmih dneh, zato je pravljica bolj kompleksna. Ko je Giovanninu izgubljen, sreča govorečega orla (slepi motiv Gilgameša), ki ga s čarobnim letom prenese h kraljični. Vendar je orel lačen, zato si Giovanninu reže kose svojega telesa, da nahrani orla. Ta motiv je psihoanalitično pomemben, ker se mora odreči infantilnemu delu sebe. Sledijo preizkušnje junaka, kraljična pošlje Giovanninu 12 zašitih srajc in vezenino na srebrnem pladnju. Ta jo uporabi kot cunjo za pospravljanje v kuhinji. Giovanninu in kraljična si postavljata dodatne pogoje. V tej epizodi pravljica spominja na Kralja Drozgobrada, saj Giovanninu predlaga, da jo ob glasbeni spremljavi nosijo v krsti z duhovnikom čez mesto do njegovega okna. Konec je srečen, sledi namreč poroka.

\footnotetext{
5 Številka pravljice v knjigi Beautiful Angiola.

6 Magnetofonske trakove Milka Matičetovega hrani Inštitut za slovensko narodopisje ZRC SAZU v Ljubljani.
} 
Dorotheina in Tinina varianta sta si podobni, rahlo se razlikujeta v zaključku. Dorotheina je bolj ljudska, Tina je dodala čustvene prvine (sramota, ubogo dekle, žalost ipd.). Čeprav sta bila brata hudobna do najmlajšega, je na koncu oče nekaj podaril tudi prvemu in drugemu sinu, najmlajšemu pa zapustil kraljestvo. Tina je dodala misel: »Po eni strani je on rešil žabo, po drugi strani pa je žaba rešila njega, saj on sam ne bi mogel ničesar doseči.« (Kropej, Dapit 2018: 84) Zaključek njene pravljice je podoben Laurinemu »Živeli so veselo in srečno, toda mi smo ostali brez centa« (Zipes 2006: 508). ${ }^{7}$

\section{SKLEPNE MISLI}

Vse tri pravljičarke - pripovedovalka Dorothea Viehmann, pisateljica Laura Gonzenbach in pripovedovalka Tina Vajtova - so imele večjezikovno in večkulturno sociokulturno ozadje: Dorothea nemško-francosko, Laura švicarsko-nemško-italijansko-sicilijansko in Tina beneško-italijansko-slovensko-rezijansko. Vse so govorile več jezikov, bile so del socialne mreže: Dorothea - gostilniški gostje, brata Grimm, Laura literarni salon in Tina - prodajalka in pripovedovalka. Maria Warner imenuje pravljice Laure Gonzenbach »sicilijanski orientalizem« (Warner 2014: 66). Vse tri so izhajale iz velikih družin, tudi same so imele številčno družino. Dorothea je bila obrtniško-trgovskega porekla, oče gostilničar, sama branjevka; Laura je bila iz visokega srednjega razreda, izobražena, pismena, kulturna; Tina je bila kmečkega porekla, delavna ženska, ki se je preživljala s prodajanjem. Zgodovinska in zemljepisna podobnost med njihovimi pravljicami je evropski prostor, razlika je v subjektivizaciji avtoric. Za Dorotheo je značilen model pripovedovanja ljudskih pravljic prve polovice 19. stoletja (jasna dihotomija med dobrim in slabim), za Lauro pisateljski model druge polovice 19. stoletja (enakopravnejši položaj

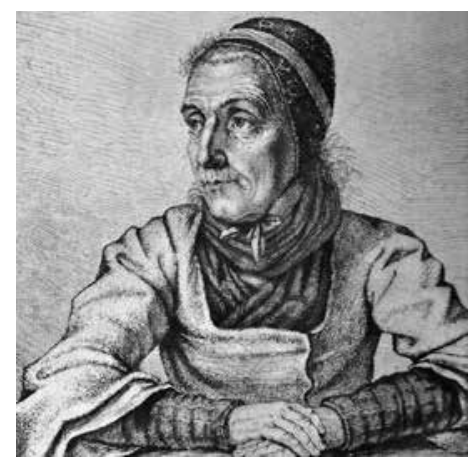

Dorothea Viehmann, Ludwig Grimm, 1815.

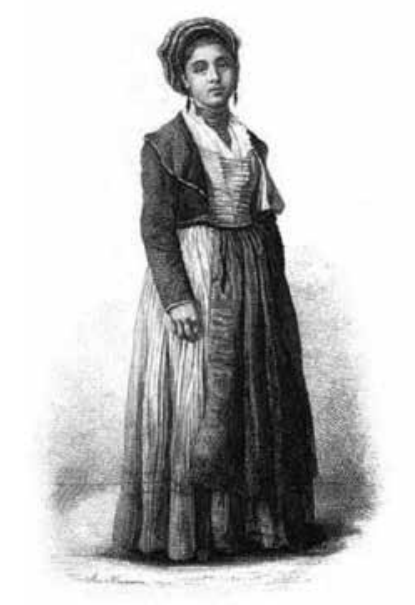

Caterina Certo (Laura Gonzenbach, Sizilianische Märchen 1870).

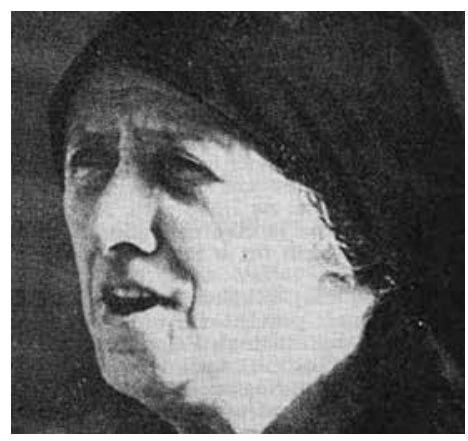

Tina Vajtova (Matičetov 1984: 187). ženskih in moških pravljičnih likov), za Tino pa model sodobnejšega pripovedovanja, vnašanje socialne empatije za glavne in stranske osebe, tako moške kot ženske.

\footnotetext{
7 »And so they lived happy and content, but we've been left without one cent« (Zipes 2006: 508).
} 
Na podlagi študija »pravljičnih« motivov trubadurk, precioz in pravljičark je ugotovljeno, da so osrednji motiv, motivni drobci in slepi motivi (Lüthi 2011: 70) izraženi v jeziku simbolov (Kristeva 1987: 1). Avtorice se izražajo z metaforami, pogost je literarni paralelizem - pozunanjanje notranje pokrajine (dobesedna in čustvena zima). Podobnosti med pesmimi trubadurk so psihopoetične vrednote: ljubezen, zaupanje, zvestoba; medtem ko so sociopoetične vrednote trubadurjev čast, ugled, velikodušnost (Sankovitch 2008: 116). Gre za podobnost med pesmimi trubadurk in pravljičark, ki se intertekstualno navezujejo na literarno kontinuiteto in na svoj način tematizirajo ljubezenske teme. Trubadurke in precioze, ki so pripadale najvišjemu sociokulturnemu sloju (aristokraciji, plemstvu), so prve od avtoric, ki so v tematiki fin'amor tematizirale ženske biografije. Za precioze, ki so večinoma živele ali pripovedovale v literarnih salonih, so bile pravljice »salonska igra«, ki so jo kodirale v pravljičnost, namenjeno odraslim, in tekst, namenjen otrokom. Tako so $\mathrm{v}$ jeziku simbolov in $\mathrm{v}$ varnem kontekstu tematizirale tabu teme, ljubezen in predvsem spolnost.

\section{LITERATURA}

Apuleius, Lucius, 1981: Metamorfoze ali Zlati osel. Prevedel, spremno besedo in opombe napisal Primož Simoniti. Ljubljana: Cankarjeva založba.

Bedenk, Kasilda, Blažić, Milena Mileva, 2019: Slovenske pravljičarke v evropskem prostoru. Ljubljana: Pedagoška fakulteta. (v tisku)

Biblija.net, 2016: Sveto pismo na internetu. Svetopisemska družba Slovenije. http://www.biblija. net/biblija.cgi?1=sl (Dostop 8. 8. 2018)

Bogin, Magda, 1976: The Women Troubadours. New York - London - Ontario: Paddington Press 1976.

Ehrhardt, Holger, 2012: Dorothea Viehmann. Die Märchenerzählerin der Brüder Grimm. Umfangreiche Dokumentation mit Beiträgen von Vera Leuschner, Heinz Rölleke u. a. Kassel: Euregio Verlag.

Kristeva, Julija, 1987: Tales of Love. New York: Columbia University Press 1987.

Kropej Telban, Monika \& Dapit, Roberto, 2018: Čudežne pravljice slovenskih pokrajin. Čarobni svet prince in vilincev. Radovljica: Didakta.

Lüthi, Max, 2011: Evropska pravljica: forma in narava. Ljubljana: Sophia.

Lüthi, Max, 1984: The Fairytale as Art Form and Portrait of Man. Bloomington: Indiana University Press.

Matičetov, Milko, 1984: In memoriam. Tina Vajtova (1900-1984). Traditiones 13, 187-194.

Matičetov, Milko \& Dapit, Roberto, 2014: Fiabe resiane - Rezijanske pravljice - Pravice po rozjansko. [Premessa, scelta del materiale sonoro e traduzioni / Spremno besedilo, izbor zvočnega gradiva in prevod Roberto Dapit, Monika Kropej; Elaborazione dei documenti sonori / Zvočna obdelava Peter Vendramin]. Ljubljana: Založba ZRC.

Nikolajeva, Maria, 2015: Reading for Learning: Cognitive approaches to children's literature. Amsterdam - Philadelphia: John Benjamins Publishing Company.

Sankovitch, Tilde, 1999. The trobairitz. In: S. Gaunt \& S. Kay (Eds.), The Troubadours: An Introduction (pp. 113-126). Cambridge: Cambridge University Press. 
Seifert, Lewis C., 2006: Fairy Tales, Sexuality, and Gender in France, 1690-1715: Nostalgic Utopias. Cambridge: Cambridge University Press.

Tatar, Maria (ed.), 1999: The Classic Fairy Tales: Texts, Criticism. New York - London: Norton \& Company.

Tomaryn Bruckner, Matilda \& Shepard Laurie, White, Laurie, 2000: Songs of the Women Troubadours. [s. 1.]: Taylor \& Francis.

Uther, Hans-Jörg, 2011: The Types of International Folktales, a Classification and Bibliography, Based on the System of Antti Aarne and Stith Thompson. FF Communications 284-286. Helsinki: Academia Scientiarum Fennica.

Warner, Marina, 2014: Once Upon a Time: A Short History of Fairy Tale. Oxford: Oxford University Press.

Ziolkowski, Jan M., 2006. Fairy tales from before fairy tales: The medieval Latin past of wonderful lies. Ann Arbor: University of Michigan.

Zipes, Jack, 2003: Beautiful Angiola: The Great Treasury of Sicilian Folk and Fairy Tales, Collected by Laura Gonzenbach. New York; London: Routledge.

Zipes, Jack, 2004: The Robber With a Witch's Head: More Stories from the Great Treasury of Sicilian Folk and Fairy Tales Collected by Laura Gonzenbach. Translated and edited by Jack Zipes. New York; London: Routledge.

Zipes, Jack, 2006: Beautiful Angiola: The Lost Sicilian Folk and Fairy Tales of Laura Gonzebach. New York: Routledge.

Zipes, Jack, 2012: The irrestistible fairy tales: the cultural and social history of a genre. Princeton - Oxford: Princeton University Press.

\section{KRATICE}

AT je mednarodna oznaka oz. akronim na osnovi priimkov dveh folkloristov Antti Aarne in Stith Thompson $(1928,1961)$, ki sta objavilia mednarodno klasificiran indeks pravljičnih tipov.

ATU je mednarodna oznaka oz. akronim na osnovi priimkov treh folkloristov Antti Aarne, Stith Thompson, Hans-Jörg Uther, ki so objavili mednarodno klasificiran indeks pravljičnih tipov (Uther 2004, ponatis 2011).

KHM je mednarodna oznaka oz. akronim na osnovi začetnic zbirke pravljice Kinder- und Hausmärchen Jacoba in Wilhelma Grimma. 
INTERCULTURALISM IN THE FAIRY TALES OF DOROTHEA VIEHMANN, LAURA GONZENBACH, AND TYNA WAJTAWA, PRESENTED ON THE EXAMPLE OF FOLKTALE TYPE THE ANIMAL BRIDE (ATU 402)

\section{Milena Mileva Blažić}

$\infty$

Dorothea Viehmann was a storyteller who told about 36 fairy tales to Jacob and Wilhelm Grimm. Socio-culturally she was of French peasant origin, and her German fairy tales also included French elements. Laura Gonzenbah was a Swiss-German storyteller who was educated, multilingual, and her Sicilian fairy tales written in German reflect interculturality (Sicilian orientalism). Resian storyteller Tyna Wajtawa (Valentina Pielich) was from the Resia valley in Italy, where a Slovenian minority lived. She narrated in Resian, that is, in a micro-language (Slovene dialect), and her fairy tales also reflect multilingualism (Italian, Slovene, Resian dialects) and interculturalism. Based on a comparative analysis of the ATU fairytale types, it was discovered that they all included in their repertoire tale type ATU 402 (animal groom/bride motif) and ATU 425 (searching for a lost husband/wife motif). The article includes a comparative analysis of the similarities and differences of the ATU 402 (The Animal Bride). The comparative analysis is of fairy tales from the collection of the Brothers Grimm, Laura Gonzenbach's book of Sicilian folktales, and Milko Matičetov's audio recordings of folktales of Tyna Wajtawa.

Despite the German, Swiss, French, Sicilian, Italian, Resian, and Slovene backgrounds of the three storytellers who have different socio-cultural backgrounds, they all share common multilingualism and interculturalism as well as the primary motifs of love and the search of happiness.

Prof. dr. Milena Mileva Blažić, Pedagoška fakultet, Univerza v Ljubljani, Kardeljeva ploščad 16, 1000 Ljubljana, Slovenija, Milena.Blazic@guest. arnes.si 